\title{
La competència matemàtica bàsica: valoració de les dificultats que manifesten els alumnes ${ }^{1}$
}

\author{
Luisa Girondo
}

Universitat Rovira i Virgili

\section{Resum}

En aquest article, s'hi esmenten les dificultats manifestades pels alumnes, en la prova d'avaluació diagnòstica relativa a l'àrea de matemàtiques, durant el curs 2010-11. I s'hi analitzen les possibles causes de les dificultats observades, per tal de veure quines millores es podrien incorporar en el treball d'aula.

Paraules clau: Avaluació diagnòstica. Ítems difícils. Càlcul. Resolució de problemes.

\section{Abstract \\ This article discusses the difficulties shown by stu- dents in the diagnostic assessment test for math- ematics in the 2010-2011 academic year and analyses the possible reasons for these difficulties so that improvements can be made to the work in the classroom.}

Key words: Diagnostic assessment. Difficult items. Calculation. Problem solving.

\section{Introducció}

Lactual llei d'educació preveu proves diagnòstiques que valorin l'aprenentatge dels alumnes en finalitzar el $4 \mathrm{t}$ curs de primària i en finalitzar el $2 n$ curs de l'ESO. La intenció s'ha de valorar com a molt positiva, ja que detectar possibles problemes d'aprenentatge i donar l'oportunitat de millorar dintre de l'etapa educativa sembla molt adequat en el pla teòric i també realitzable en el pla de la praxis educativa.

D’aquestes proves, que elabora l'administració educativa i que gestionen i corregeixen els centres mateix, ja se n'han fet unes quantes edicions aquí, a Catalunya - almenys en les àrees de llengües i de matemàtiques. En aquest article us hi presentem un estudi de les dificultats que han manifestat els alumnes en la prova diagnòstica de làrea de matemàtiques en l'edició del curs 2010-11. Per qüestions pràctiques, es va passar, durant l'octubre de 2010, als alumnes que iniciaven el 5è curs de primària.

Analitzar les dificultats que manifesten els alumnes, quan han de resoldre una determinada tasca escolar, és una manera que tenim els ensenyants d'esbrinar el nivell de competència matemàtica manifestada pel discent. D’aquí en podem treure les causes o motius de tipus acadèmic que provoquen aquestes dificultats i valorar si s'hi pot incidir de manera positiva per millorar-les.

1 En aquest treball hi han collaborat els membres de l'equip de Formadors de Matemàtiques de Primària (2010-11) de l'ICE de la URV. 
Aquest és, a gran trets, l'objectiu del treball que us presentem. S'han recollit les respostes als diferents ítems de matemàtiques que han estat objecte de la prova diagnòstica. I, una vegada analitzades aquestes respostes (respectant els criteris d'avaluació que la prova mateix subministrà als centres), hem analitzat les possibles causes de dificultat en els ítems que presenten major percentatge d'error.

El total de proves revisades han estat 162 , corresponents a 162 alumnes de 7 escoles diferents. S'han triat escoles que tinguessin un nivell socioeconòmic similar. Entre elles, hi ha un centre concertat, centres de poblacions de més de cent mil habitants i centres de poblacions de menys de deu mil habitants. Tots de les comarques tarragonines.

\section{Procediment}

S'han analitzat les respostes a cada ítem de la prova dels 162 alumnes, corresponents als 7 centres.

Cal aclarir que la prova presenta, als alumnes, 10 activitats, cada una de les quals, però, es pot assignar a diferents blocs del currículum de l'àrea (com ara càlcul, problemes, mesura, etc.) i presenta diversos ítems. Només una activitat correspon a un sol ítem analitzat, (precisament de l'apartat "Problemes").

En certa manera, aquell recull ha estat un dels punts negatius de la realització. De fet, aquest treball que presentem pretén estudiar els errors de la prova i les seves causes, i no pas els encerts. Per tant, hem recollit els ítems que no tenen la resposta correcta (ítems de càlcul) o ítems que calia qualificar, quan aquesta qualificació no arribava a l'aprovat.

Aquestes dades ens donen una taula d'errors per a cada un dels ítems que us presentem a la taula núm. 1. Els ítems de càlcul s'expliciten completament a la taula; però, per als ítems amb enunciat llarg, es descriu una referència. S’aconsella, al lector que vulgui fer un seguiment més acurat, que tingui a l'abast el dossier de la prova, que es troba a la plana del Departament d'Ensenyament, a l'apartat del Consell Superior d'Avaluació.

$<$ http://www20.gencat.cat/portal/site/ensenyament>

La segona columna de la taula mostra cada ítem de la prova; la tercera columna, el percentatge d'alumnes que s'hi han equivocat i la quarta columna ressalta els ítems que seran objecte de valoració, vistos els seus, relativament, alts percentatges d'error.

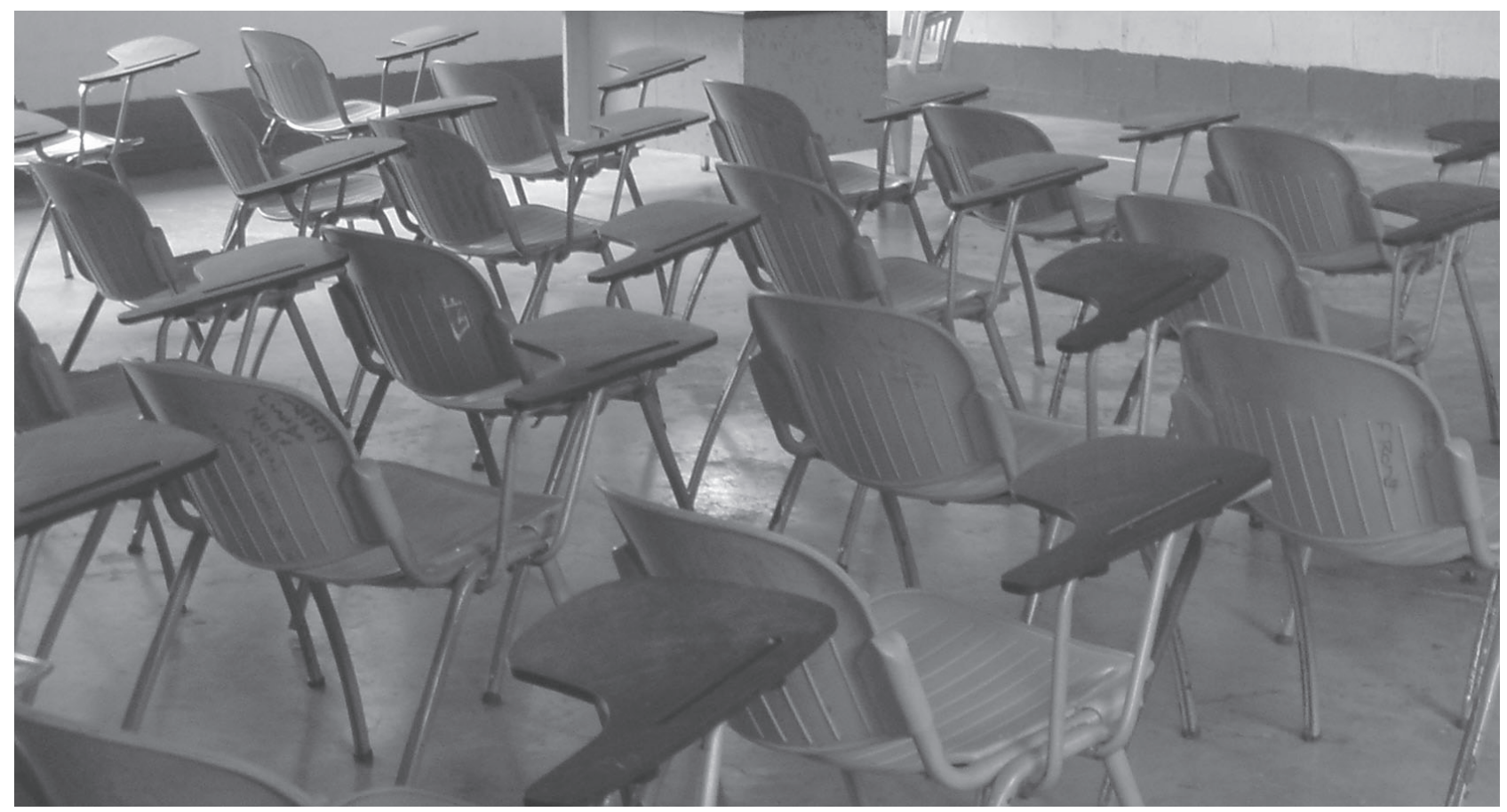




\begin{tabular}{|c|c|c|c|}
\hline núm. act. & activitat & $\begin{array}{c}\% \\
\text { d'errors }\end{array}$ & $\begin{array}{c}\text { A } \\
\text { considerar }\end{array}$ \\
\hline \multicolumn{4}{|c|}{ Activitat 1} \\
\hline 1.1 .1 & $380+20+60$ & $7,41 \%$ & \\
\hline 1.1.2 & $625+\ldots 0735$ & $15,43 \%$ & \\
\hline 1.1 .3 & $585-60$ & $15,43 \%$ & \\
\hline 1.1 .4 & $117-\ldots=90$ & $39,51 \%$ & \\
\hline 1.1 .5 & $13 \times 4$ & $24,69 \%$ & \\
\hline 1.1 .6 & $13 \times 10$ & $14,82 \%$ & \\
\hline 1.1 .7 & $13 \times 14$ & $49,38 \%$ & $49,38 \%$ \\
\hline 1.1 .8 & $25 x \ldots=100$ & $54,32 \%$ & $54,32 \%$ \\
\hline 1.1 .9 & $\ldots \ldots=5$ & $33,33 \%$ & \\
\hline 1.2 .1 & $\ldots+\ldots=20$ & $24,69 \%$ & \\
\hline 1.2 .2 & $\ldots+\ldots=50$ & $19,75 \%$ & \\
\hline 1.2 .3 & $\ldots+\ldots=100$ & $29,63 \%$ & \\
\hline 1.2 .4 & $\ldots+\ldots=200$ & $33,33 \%$ & \\
\hline 1.2 .5 & $\ldots-\ldots=20$ & $40,12 \%$ & \\
\hline 1.2 .6 & $\ldots-\ldots=100$ & $43,21 \%$ & \\
\hline 1.2 .7 & $\ldots-\ldots=200$ & $45,06 \%$ & \\
\hline 1.2 .8 & $\ldots-\ldots=1000$ & $48,15 \%$ & $48,15 \%$ \\
\hline 1.3 .1 & $24 \ldots 240$ & $32,10 \%$ & \\
\hline 1.3 .2 & $240 \ldots 120$ & $27,16 \%$ & \\
\hline 1.3 .3 & $120 \ldots 100$ & $17,28 \%$ & \\
\hline 1.3 .4 & $100 \ldots 25$ & $38,89 \%$ & \\
\hline 1.3 .5 & $25 \ldots 60$ & $33,95 \%$ & \\
\hline 1.3 .6 & $60 \ldots 6$ & $38,89 \%$ & \\
\hline 1.3 .7 & $6 \ldots 12$ & $16,67 \%$ & \\
\hline \multicolumn{4}{|c|}{ Activitat 2} \\
\hline $2.1(0-6)$ & $\begin{array}{l}\text { cub/esfera/ } \\
\text { cilindre }\end{array}$ & $22,84 \%$ & \\
\hline $2.2(0-3)$ & capses (22 kg) & $24,07 \%$ & \\
\hline \multicolumn{4}{|c|}{ Activitat 3} \\
\hline 3.1 & sèrie +5 & $8,02 \%$ & \\
\hline 3.2 .1 & $\ldots+\ldots=40$ & $14,20 \%$ & \\
\hline 3.2 .2 & $\ldots+\ldots=41$ & $18,52 \%$ & \\
\hline 3.2 .3 & $\ldots+\ldots=32$ & $48,77 \%$ & $48,77 \%$ \\
\hline 3.2 .4 & $\ldots+\ldots=33$ & $52,47 \%$ & $52,47 \%$ \\
\hline $3.3 \mathrm{a} / \mathrm{b}$ & 6è dia & $30,86 \%$ & \\
\hline $3.3 \mathrm{a} / \mathrm{b}$ & 8 è dia & $27,78 \%$ & \\
\hline
\end{tabular}

\begin{tabular}{|c|c|c|c|}
\hline núm. act. & activitat & $\begin{array}{c}\% \\
\text { d'errors }\end{array}$ & $\begin{array}{c}A \\
\text { considerar }\end{array}$ \\
\hline \multicolumn{4}{|c|}{ Activitat 4} \\
\hline $4.1 \mathrm{a}$ & & $25,93 \%$ & \\
\hline $4.1 \mathrm{~b}$ & & $12,35 \%$ & \\
\hline $4.1 c$ & & $20,99 \%$ & \\
\hline $4.1 \mathrm{~d}$ & comprar bistec & $78,40 \%$ & $78,40 \%$ \\
\hline $4.2(0-4)$ & text & $29,01 \%$ & \\
\hline $4.3(0-3)$ & segment i long. & $25,31 \%$ & \\
\hline \multicolumn{4}{|c|}{ Activitat 5} \\
\hline $5.1 \mathrm{marca}$ & $2 D / 3 D$ & $67,90 \%$ & $67,90 \%$ \\
\hline $5.1(0-4)$ & comparar figures & $52,47 \%$ & $52,47 \%$ \\
\hline $5.2(0-2)$ & meitats & $33,33 \%$ & \\
\hline \multicolumn{4}{|c|}{ Activitat 6} \\
\hline 6.1 num & $\begin{array}{l}\text { resultat fora de } \\
95-105\end{array}$ & $34,57 \%$ & \\
\hline $6.1(0-5)$ & $\begin{array}{c}\text { explicar què s'ha } \\
\text { fet }\end{array}$ & $61,73 \%$ & $61,73 \%$ \\
\hline $6.2(0-4)$ & situar a la recta & $61,11 \%$ & $61,11 \%$ \\
\hline \multicolumn{4}{|c|}{ Activitat 7} \\
\hline $7.1(0-3)$ & $\begin{array}{l}\text { problema } \\
\text { monedes }\end{array}$ & $24,69 \%$ & \\
\hline $7.2(0-4)$ & $\begin{array}{c}\text { escriure } \\
\text { problema } 6 \times 10\end{array}$ & $43,83 \%$ & \\
\hline \multicolumn{4}{|c|}{ Activitat 8} \\
\hline $8.1(0-5)$ & $15 \times 615+15 \ldots$ & $70,37 \%$ & $70,37 \%$ \\
\hline \multicolumn{4}{|c|}{ Activitat 9} \\
\hline 9.1 .1 & un pastís & $18,52 \%$ & \\
\hline 9.1 .2 & dos pastissos & $20,99 \%$ & \\
\hline 9.1 .3 & un quart & $30,25 \%$ & \\
\hline 9.1 .4 & $\begin{array}{c}1,5 \text { pastissos } \\
(1.800 \mathrm{~g})\end{array}$ & $51,85 \%$ & $51,85 \%$ \\
\hline 9.1 .5 & tres pastissos & $42,59 \%$ & \\
\hline 9.2 .1 & $2 P$ lectura directa & $53,09 \%$ & $53,09 \%$ \\
\hline 9.2 .2 & $3 \mathrm{P}$ suma de tot & $64,20 \%$ & $64,20 \%$ \\
\hline \multicolumn{4}{|c|}{ Activitat 10} \\
\hline $10.1(0-5)$ & $\begin{array}{c}\text { Prob. Noemí i } \\
\text { Sergi }\end{array}$ & $48,77 \%$ & $48,77 \%$ \\
\hline
\end{tabular}


Com s'observa, hem seleccionat els ítems que donen un \% d'error al voltant del 50\% (exactament, superior al $48 \%$ ) o un nombre superior. A aquests ítems, els en direm "ítems amb majors dificultats".

\section{Valoració dels 15 ítems amb majors dificultats}

Taula núm. 2: Activitats 1 i 3

(càlcul i relacions numèriques)

\begin{tabular}{|c|c|c|}
\hline Núm. & Activitat & \% error \\
\hline 1.1 .7 & $13 \times 14=\square$ & $49,38 \%$ \\
1.1 .8 & $25 \times \square=100$ & $54,32 \%$ \\
\hline 1.2 .8 & $\square=1.000$ & $48,15 \%$ \\
\hline 3.2 .3 & $\square=32$ & $48,77 \%$ \\
3.2 .4 & $\square+\square=33$ & $52,47 \%$ \\
\hline
\end{tabular}

De manera general, aquesta dificultat sobserva en tots els centres analitzats. Només hi ha algunes excepcions (com ara l'activitat 5.1, que dóna un percentatge total d'error prop del $52,5 \%)$, però hi ha un centre en què el percentatge d'error és molt inferior (8\%). Lògicament els percentatges d'error són diferents en cada centre. Per a un mateix ítem, hi pot haver fins a 30 punts percentuals de diferència; però, de manera relativa, excepte algun dels ítems de càlcul (1.1.8 o 1.2.8), en tots el centres, els 15 ítems seleccionats han estat dels de major dificultat per a cada centre, cosa que indica una certa dificultat objectiva de l'ítem.

En els resultats de $3 \times 14$ i de $3 \times 10$, anteriors immediatament a l'ítem $3 \times 14$, no s'hi aprecia que siguin aprofitats per deduir el següent. Es valora que als centres s'hi treballen poc les habilitats de càlcul relacionades a copsar relacions; això safavoriria en aquest cas, si els tres ítems haguessin estat presentats com un tot, com es mostra al següent gràfic. De totes maneres, no veiem que la presentació sigui la causa exclusiva de no aprofitar els resultats anteriors i fer la suma corresponent, sinó que més aviat sembla que la causa en sigui una manca d'aquesta estratègia en molts alumnes.

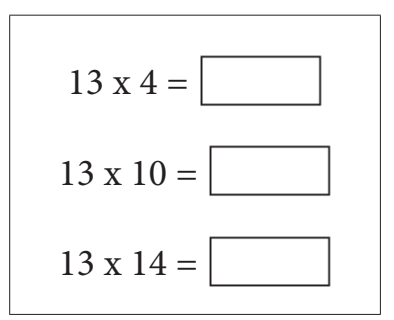

Pel que fa a l'elevat nombre d'errors en l'activitat 1.1.8, no sembla gaire justificable que els alumnes d'aquest nivell no tinguin mecanitzat el coneixement de la relació multiplicativa entre 25 i 100. Pensar que ara no hi ha aquesta relació en la moneda i que, per tant, és poc utilitzada no és adient, ja que es tracta d'una relació fonamental com a quarta part de cent, i del tot necessària per calcular i relacionar quarts i percentatges, que s'estudiaran després.

Lactivitat 1.2.8, que demana de trobar dos nombres que no siguin nombres acabats en zeros i que tinguin per diferència mil, és una activitat lligada al coneixement de les pautes del sistema de numeració. Només calia trobar dos nombres de quatre xifres (en un, amb les xifres iguals, i en l'altre, en la posició d'unitats, desenes i centenes) que es diferencien en una unitat en la xifra dels milers. Tal vegada, la magnitud del nombre - de quatre xifres i no tan sols de tres- ha resultat massa gran pels alumnes.

Sorprèn la dificultat que comporta descompondre 32 en dues meitats, quan s'havia fet amb èxit l'anterior del 40. Es valora que els alumnes també hagin pogut perdre l'atenció en la condició que els dos sumands fossin iguals - valoració que fem pel tipus de respostes que hem vist. Lògicament la qüestió 3.2.4 fa que també fallin en la 3.2.5.

\section{Taula núm. 3: Activitat 4d (mesura)}

\begin{tabular}{|c|c|c|}
\hline Núm. & Activitat & \% error \\
\hline 4.1d & d. la quantitat de carn d'un bistec & $78,40 \%$ \\
\hline
\end{tabular}

Els alumnes havien de dir en quina unitat mesurarien diferents quantitats de magnitud. Lactivitat pot tenir dues equivocacions: que la unitat triada no correspongui a la magnitud o que la unitat triada no sigui la més convenient per la grandària que ens proposen. En el cas de la 
prova, aquesta activitat presenta baixes puntuacions, a causa de la no-adequació de la unitat a la grandària. Els alumnes trien majoritàriament el kg, en comptes del g, com preveien els criteris d'avaluació. En aquest cas, es valora excessivament estricte el criteri d'avaluació, ja que el pes d'un bistec a la pràctica es pot visualitzar com a $0,2 \mathrm{~kg}$; tot i que, en verbalitzar-ho, sí que és més freqüent dir « $200 \mathrm{~g} »$.

Només marcant les dues figures amb volum, l'activitat ja estava superada. Però no és aquesta la resposta de la majoria dels alumnes analitzats. Per això, vam separar els resultats d'aquesta activitat en dues parts: en la primera, hi mostrem el percentatge d'alumnes que no marquen les dues figures amb volum (67.90\%), i en la segona, els resultats de les argumentacions donades pels alumnes per defensar les dues figures que s'assemblen més (52,47\% d'errors).

Lògicament, en aquest segon percentatge, hi ha inclòs el gairebé 32\% d'encerts dels alumnes que fan la creueta en els dos volums, la qual cosa indica que molt pocs alumnes - al voltant del $15 \%$ - fan un discurs en què utilitzen el vocabulari geomètric de manera precisa i que els serveix per argumentar en què s'assemblen un quadrat i un cub, o dues figures amb volum. En el treball geomètric, la nostra tradició pedagògica és poc exigent amb la verbalització i, per tant, els alumnes no tenen eines suficients per justificar les seves respostes.
Aquestes dues activitats presenten resultats dèxit relativament baixos, segurament perquè no les atenen gaire en la pràctica escolar. Els currículums ja indiquen, fa temps, la importància del càlcul estimatiu com una part del denominat càlcul mental; però encara preval l'aritmètica escrita i se'n treballen poc les estratègies i les verbalitzacions. Això explicaria l'elevat nombre d'errors en l'activitat 6.1. Per interpretar-la millor, hem considerat separat l'ítem de trobar els dos nombres que sumats s'aproximin a 100 (interval 95-105). Com es pot veure a les dades de la taula 1 , al voltant d'un 35\% dels alumnes analitzats no han estat capaços de trobar aquesta suma.

Lògicament, una vegada trobada la suma, demanar que es raoni com s'ha pensat és afegir dificultat a l'ítem global.

Pel que fa a l'activitat de situar nombres a la recta, és una activitat relacionada amb la temàtica de les lectures d'escales en gràfics, tan utilitzades avui en dia. Però, a més, és un recurs excel.lent perquè els alumnes captin relacions numèriques elementals (proximitat, complement a, doble...) necessàries per assolir habilitats de càlcul mental. En aquest ítem, que exigia marcar el punt mitjà del segment donat, s'hi ha observat una major dificultat, i no tant en el següent, que indicava situar el punt 200 a l'interval 160-210. Es valora que en la correcció s'hagi estat més exigent en el cas del punt mitjà, que era més fàcil de comprovar que en el segon cas, en què s'han donat per bones aproximacions laxes.

Taula núm. 4: Activitat 5.1 (geometria)

\begin{tabular}{|c|c|c|}
\hline Núm. & Activitat & $\%$ error \\
\hline 5.1 & Marca amb una $\mathrm{X}$ les dues figures que s'assemblen més. & $\begin{array}{l}67,90 \% \\
52,47 \%\end{array}$ \\
\hline
\end{tabular}


Taula núm. 5: Activitat 6. Aproximació

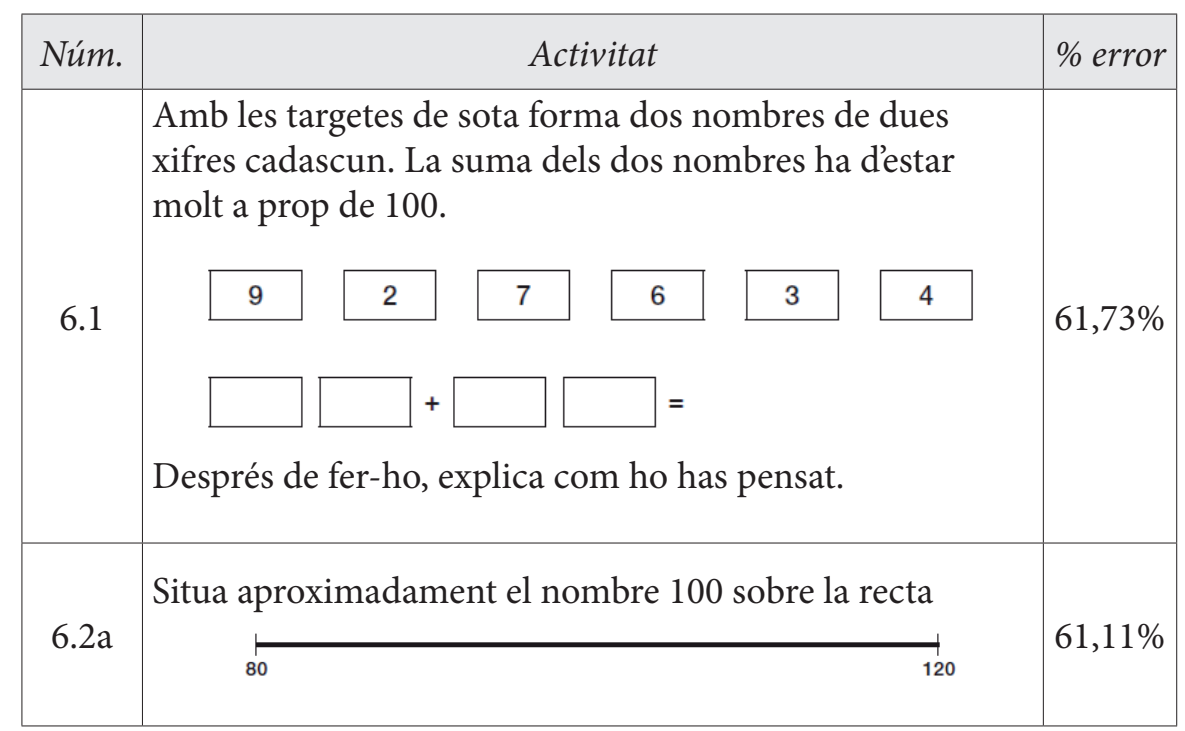

Taula núm. 7: Activitat 8. Estratègies de càlcul

\begin{tabular}{|c|l|l|}
\hline$N^{o}$ & \multicolumn{1}{|c|}{ Activitat } & \% error \\
\hline \multirow{3}{*}{8.1} & $\begin{array}{l}\text { El Pau vol saber els llapis que hi ha en 6 capses. Cada } \\
\text { capsa conté 15 llapis. Creu que ha de fer loperació 16 x 6, } \\
\text { però no recorda les taules de multiplicar. } \\
\text { Ell ho ha fet d'aquesta manera: } \\
15+15+15=45 \\
45+45=90 \\
\end{array}$ & $70,37 \%$ \\
& $\begin{array}{l}\text { Et sembla que ho ha fet bé? Explica el perquè. } \\
\end{array}$ & \\
\hline
\end{tabular}

Per tant, valorem que tota aquesta activitat 6.2 també és treballa poc a les aules, fet que justificaria els errors observats.

Aquesta activitat és la que ha resultat més difícil als alumnes observats. A la vista del tipus d'error que han comès, hem copsat que molts alumnes no han entès què els demanaven. Argumentar si el càlcul realitzat era equivalent a multiplicar $15 \times 6$. Segurament, aquest procés de raonament, que implica l'equivalència entre càlculs de suma i de producte, no s'ha treballat prou encara. És un aspecte més de les habilitats de càlcul mental que cal desenvolupar en aquesta etapa i que són necessàries per al ciutadà d'avui en dia. És clar, això implica situar el centre de gravetat del càlcul en el càlcul mental, i no en els procediments algorísmics escrits, com és tradició en les nostres pràctiques pedagògiques.

Llegir una informació d'una taula és una activitat que resulta relativament fàcil a la majoria dels alumnes. En el cas de l'activitat 9.1, ha resultat difícil establir una relació entre el pes de mig pastís (600 g) — que és la primera dada de la taula i segurament la que prenen de referència per calcular-ne la resta- i els $1.800 \mathrm{~g}$ de l'ítem problema. Establir que tres meitats de pastís equivalen a un pastís i mig no és clar que hagi de ser encara una dificultat en aquest nivell; però, a la vista dels resultats, sí que ho ha estat.

Lactivitat 9.2 l'hem valorada com a dos ítems diferents. El primer demana formular una pregunta perquè la resposta sigui «40». Com que 
Taula núm. 8: Activitat 9. Informació taula i gràfic

\begin{tabular}{|c|c|c|c|c|}
\hline Núm. & \multicolumn{3}{|c|}{ Activitat } & $\%$ error \\
\hline \multirow{8}{*}{9.1} & \multicolumn{3}{|c|}{$\begin{array}{l}\text { Mig pastís de xocolata pesa } 600 \text { grams. } \\
\text { Completa la taula: }\end{array}$} & \multirow{8}{*}{$51,85 \%$} \\
\hline & \multirow{7}{*}{ or } & Quantitat de pastís & Pes en grams & \\
\hline & & Mig pastís & 600 & \\
\hline & & Un pastís sencer & & \\
\hline & & Dos pastissos & & \\
\hline & & & 300 & \\
\hline & & & 1.800 & \\
\hline & & Tres pastissos & & \\
\hline \multirow{6}{*}{9.2} & \multirow{5}{*}{\multicolumn{3}{|c|}{$\begin{array}{l}\text { En la festa de l'escola s'han venut pastissos. El gràfic de } \\
\text { barres mostra la quantitat de pastissos que s'han venut } \\
\text { de cada gust. } \\
\text { Mira el gràfic i escriu una pregunta en què la resposta } \\
\text { sigui } 40 \text {. }\end{array}$}} & \multirow{5}{*}{$53,09 \%$} \\
\hline & & & & \\
\hline & & & & \\
\hline & & & & \\
\hline & & & & \\
\hline & \multicolumn{3}{|c|}{$\begin{array}{l}\text { I escriu també una pregunta en què la resposta sigui } \\
100 .\end{array}$} & $64,20 \%$ \\
\hline
\end{tabular}

Taula núm. 9: Activitat 10. Problema (comparar)

\begin{tabular}{|c|c|c|c|}
\hline Núm. & \multicolumn{2}{|c|}{ Activitat } & $\begin{array}{c}\% \\
\text { error }\end{array}$ \\
\hline 10 & 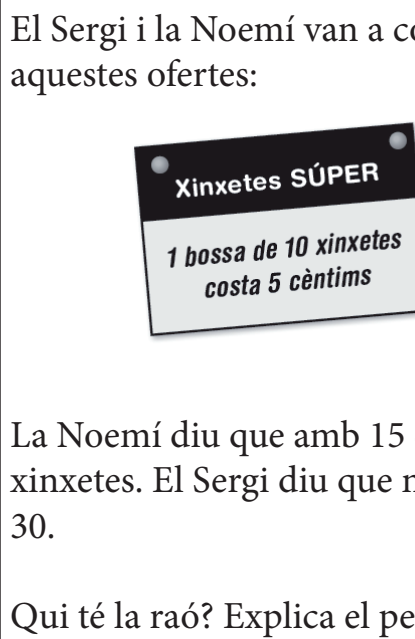 & $\begin{array}{l}\text { mprar xinxetes. Troben } \\
\text { Xinxetes PUNXA } \\
\begin{array}{c}\text { bossa de } 25 \text { xinxetes } \\
\text { costa } 10 \text { cèntims }\end{array} \\
\text { èntims poden comprar } 35 \\
\text { més en poden comprar } \\
\text { què. }\end{array}$ & $48,77 \%$ \\
\hline
\end{tabular}


una freqüència té aquest valor, n'hi ha prou de formular una pregunta directa. Als criteris d'avaluació s'hi exigia una correcció gramatical; valorem que és per culpa de la manca de capacitat expressiva dels alumnes que hagin fallat, però que no és causa de l'error observat, el raonament lògic matemàtic que implicava. No obstant això, no volem considerar que no sigui desitjable aquest nivell d'exigència; "saber expressar" és imprescindible per assolir conceptes i procediments que són estables en el temps i que a més són funcionals.

Si aquesta primera part de l'activitat presenta un error del 53\%, aquest error ja contribueix al $64 \%$ d'error de la valoració global de l'activitat en un percentatge important. De tota manera, del segon ítem d’aquesta activitat, a més de la possible dificultat lingüística — ja comentada-, se n'ha de valorar que la pregunta que hi cal formular ja no és una lectura directa del gràfic, sinó que cal fer-hi alguna operació amb les informacions visuals $i$, per tant, hi ha una major dificultat matemàtica.

És difícil intentar justificar que no és un problema adequat al nivell, tant pel que fa a la presentació de la informació (el text no és complicat), com pel que fa a la lògica matemàtica que requereix (fer una comparació) o als nombres i càlculs que hi estan implicats. Encara que aquesta anàlisi de dificultat ens fa pensar que la dificultat és baixa, les respostes dels alumnes observats no indiquen que hagi estat fàcil. La resolució de problemes - entesa com el procés de comprendre de manera autònoma enunciats, elaborar mentalment un pla de resolució i portar-lo a terme, tot controlant si les respostes són o no coherents per al cas plantejat- és una feina que cal practicar molt en les aules de matemàtiques. Els alumnes han de guanyar confiança en les seves pròpies capacitats de raonament quantitatiu en situacions quotidianes, i això només s'aconseguirà si aquestes situacions es presenten a l'aula i es treballen de manera continuada — si es vol que un gran nombre d'alumnes adquireixin aquesta capacitat.

Vull agrair als companys del Grup de Formadors de Matemàtiques (F. Alegria, L. Cabello, G. Canosa, P. Besora, M. Domènech, F. Munté i A. Hernàndez) la seva col-laboració en aquest treball. Faig extensiu el mateix agraïment a les set escoles que ens han facilitat l'accés a les proves. I també als alumnes de $3 \mathrm{r}$ curs de primària (2010-11) Jordi Martínez i Raimon Ferrerons, per la seva ajuda en la recollida de dades.

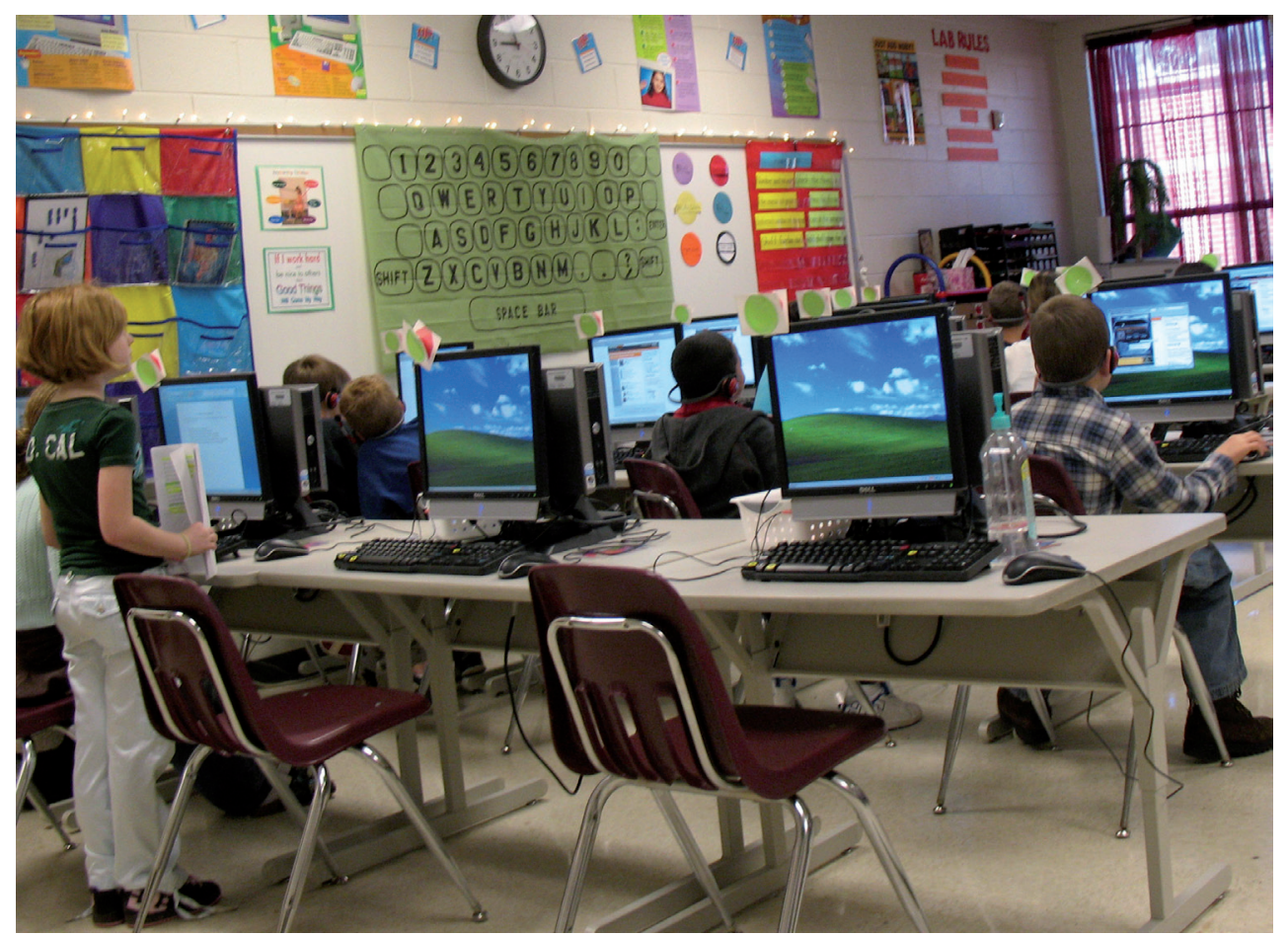

